\title{
BoHV-4-based vector delivering Ebola virus surface glycoprotein
}

\author{
Alfonso Rosamilia', Sarah Jacca' , Giulia Tebaldi', Silvia Tiberti ', Valentina Franceschi' , Francesca Macchi' \\ Sandro Cavirani ${ }^{1}$, Gary Kobinger ${ }^{2}$, Donald P. Knowles ${ }^{3}$ and Gaetano Donofrio ${ }^{1 *}$ (D)
}

\begin{abstract}
Background: Ebola virus (EBOV) is a Category A pathogen that is a member of Filoviridae family that causes hemorrhagic fever in humans and non-human primates. Unpredictable and devastating outbreaks of disease have recently occurred in Africa and current immunoprophylaxis and therapies are limited. The main limitation of working with pathogens like EBOV is the need for costly containment. To potentiate further and wider opportunity for EBOV prophylactics and therapies development, innovative approaches are necessary.

Methods: In the present study, an antigen delivery platform based on a recombinant bovine herpesvirus 4 (BoHV-4), delivering a synthetic EBOV glycoprotein (GP) gene sequence, BoHV-4-syEBOVgD106 $\triangle T K$, was generated.

Results: EBOV GP was abundantly expressed by BoHV-4-syEBOVgD106 $\triangle T K$ transduced cells without decreasing viral replication. BoHV-4-syEBOVgD106 $\triangle T K$ immunized goats produced high titers of anti-EBOV GP antibodies and conferred a long lasting (up to 6 months), detectable antibody response. Furthermore, no evidence of BoHV-4syEBOVgD106 $\triangle T K$ viremia and secondary localization was detected in any of the immunized animals.
\end{abstract}

Conclusions: The BoHV-4-based vector approach described here, represents: an alternative antigen delivery system for vaccination and a proof of principle study for anti-EBOV antibodies generation in goats for potential immunotherapy applications.

Keywords: Ebola virus, Bovine herpesvirus 4, Vaccine platform, Viral vector, Recombineering

\section{Background}

Ebola virus (EBOV) is a pathogen responsible of outbreaks of human hemorrhagic fever in African countries, including the last epidemic, which ended with more than 11,300 deaths in Guinea, Liberia and Sierra Leone (updated since September 20th; http://apps.who.int/ ebola/ebola-situation-reports). EBOV infection is characterized by systemic viral replication, host immunity hyper responsiveness along with a cytokine storm and disseminated intravascular coagulation similar to septic shock [1]. EBOV belongs to the Filoviridae family which includes two genera, Ebolavirus and Marburgvirus. The genus Ebolavirus includes three species pathogenic in

\footnotetext{
*Correspondence: gaetano.donofrio@unipr.it

1 Department of Medical-Veterinary Science, University of Parma, Via del

Taglio 10, 43126 Parma, Italy

Full list of author information is available at the end of the article
}

humans, Zaire ebolavirus [case fatality report (CFR) 70-90\%]; Sudan ebolavirus (CFR 50\%) and Bundibugyo ebolavirus (CFR 25\%) [2].

Vaccine production and availability is widely dependent on commercial factors. Indeed, it is not a mere coincidence if vaccines dedicated to important diseases of undeveloped countries are less prevalent on the market than those for diseases of developed countries. An important exception could be represented by EBOV vaccines. Although the disease has been known by the scientific community since 1976, an effective, commercially available vaccine is still lacking. The recent EBOLA outbreak, which began in December 2013, affected both people in isolated rural areas and in large cities. The outbreak reached global dimensions and EBOV-infected patients have been hospitalized not only in Africa but also in USA and Europe. This phenomenon captured the attention of the global scientific community. However, 
research activity in this field is hampered by the need of costly facilities which is the most important issue in dealing with infectious pathogens for which there are few available vaccines and no effective treatment.

So far a dozen vaccines proved effective protection in non-human primates from lethal EBOV infection and several ones are in advanced trial phases. Most of these vaccine approaches are viral vector-based, where the immune-dominant full length membrane glycoprotein (GP) open reading frame is delivered by a recombinant viral vector. Platforms based on recombinant adenovirus serotype 5 (rAd5) vectors [3], combined DNA/ rAd5 vectors [4], combined rAd serotype 26 and 35 vectors, recombinant chimpanzee adenovirus serotype 3 (rChAd3) vectors [3], alphavirus replicons based on recombinant human parainfluenza virus 3 (rHPIV3) [5], rabies virus [6], and recombinant vesicular stomatitis virus (sVSV) [7], have been exploited with successful results [8]. Vectorialized viruses are not only mere delivery systems but also a sort of adjuvant which strongly induce an active immunity. There are several types of viral vectors, derived from different classes of viruses and each of them possess particular characteristics. It is therefore difficult to predict which virus will best achieve the vaccine-vector goal. It must be kept in mind that a specific viral-vector could be suitable for the immunization toward a specific pathogen, but not toward others. Consequently, it would be of great interest to explore new vaccine-vector agents based on different viruses. Bovine herpesvirus 4 (BoHV-4)-is a relatively new viral vector derived from bovine gammaherpesvirus. Recombinant BoHV-4s cloned as bacterial artificial chromosome (BAC), delivering ORFs coding for immune-dominant antigens from different pathogens, were shown to successfully elicit a functional immune-response in mice $[9,10]$, rats [11], rabbits [12], sheep [13], swine [14] and goats [15]. In the present paper, a BoHV-4-based vector platform was generated exploiting a synthetic gene approach; a recombinant BoHV-4 delivering EBOV GP ORF expression cassette was constructed and goats were successfully immunized.

\section{Methods}

\section{Cell lines}

Bovine embryo kidney [(BEK) were from Dr. M. Ferrari, Istituto Zooprofilattico Sperimentale, Brescia, Italy; (BS CL-94)], BEK expressing cre recombinase (BEK cre) [16] and human embryo kidney 293T [(HEK 293T) ATCC: CRL-11268] cell lines were cultured in complete growth medium Eagle's minimal essential medium (EMEM, LONZA) containing $10 \%$ fetal bovine serum (FBS), $2 \mathrm{mM}$ of L-glutamine (SIGMA), $100 \mathrm{IU} / \mathrm{mL}$ of penicillin (SIGMA), $100 \mu \mathrm{g} / \mathrm{mL}$ of streptomycin (SIGMA) and
$2.5 \mu \mathrm{g} / \mathrm{mL}$ of Amphotericin B (SIGMA) and incubated at $37^{\circ} \mathrm{C}, 5 \% \mathrm{CO}_{2}$.

\section{Constructs}

Synthetic Zaire Ebola virus Mayinga glycoprotein (GP) ORF, tagged at the carboxy-terminal with gD106 peptide (syEBOVgD106) was excised from pUC57sy EBOVgD106 (EUROFINS, GENOMICS) with NheI and SmaI enzymes and the $2153 \mathrm{bp}$ fragment was inserted inside NheI/SmaI cut pINT2EGFPTK shuttle vector [17] to generate pINT2CMVsyEBOVgD106. EBOV secreted fragment (EBOVsec), without the transmembrane domain, was obtained by amplification from pINT2CMVsyEBOVgD106 with NheI EBOGP sense (5'ggggctagcccaccatgggcgtg- $3^{\prime}$ ) and SalI EBOGP antisense (5'-ggggtcgacctggcgccagccggtccaccagtt $3^{\prime}$ ) primers. The generated $1967 \mathrm{bp}$ NheI-EBOsec-SalI was inserted inside NheI/SalI digested pIgkE2gD106 to obtain the pCMVEBOsecgD106 construct.

\section{Transient transfection}

Confluent HEK 293T cells were seeded into six well plates $\left(3 \times 10^{5}\right.$ cells/well $)$ and incubated at $37^{\circ} \mathrm{C}$ with $5 \% \mathrm{CO}_{2}$. When the cells were sub-confluent, the culture medium was removed and the cells were transfected with pINT2CMVsyEBOVgD106 using polyethylenimine (Pei) transfection reagent (POLYSCIENCES, INC.). Briefly, $3 \mu \mathrm{g}$ of DNA were mixed with $7.5 \mu \mathrm{g}$ PEI $(1 \mathrm{mg} / \mathrm{mL})$ (ratio 1:2.5 DNA-Pei) in $200 \mu \mathrm{L}$ of Dulbecco's modified essential medium (DMEM) high glucose (EUROCLONE) without serum. After 15 min at RT, $800 \mu \mathrm{L}$ of medium without serum were added and the transfection solution was transferred to the cells and left for $6 \mathrm{~h}$ at $37^{\circ} \mathrm{C}$ with $5 \% \mathrm{CO}_{2}$, in a humidified incubator. The transfection mixture was then replaced with fresh medium (EMEM, with $10 \% \mathrm{FBS}, 50 \mathrm{IU} / \mathrm{mL}$ of penicillin, $50 \mu \mathrm{g} / \mathrm{mL}$ of streptomycin and $2.5 \mu \mathrm{g} / \mathrm{mL}$ of Amphotericin B) and incubated for $24 \mathrm{~h}$ at $37^{\circ} \mathrm{C}$ with $5 \% \mathrm{CO}_{2}$.

\section{Viruses and viral replication}

BoHV-4-syEBOVgD106 $\Delta$ TK and BoHV-4-A were propagated by infecting confluent monolayers of BEK cells at a multiplicity of infection (MOI) of 0.5 tissue culture infectious doses 50 (TCID50) per cell and maintained in medium with only $2 \%$ FBS for $2 \mathrm{~h}$. The medium was then removed and replaced with fresh EMEM containing $10 \%$ FBS. When the cytopathic effect (CPE) affected the majority of the cell monolayer ( $72 \mathrm{~h}$ post infection), the virus was prepared by freezing and thawing cells three times and pelleting the virions through a $30 \%$ sucrose cushion, as described previously [18]. Virus pellets were then resuspended in cold EMEM without FBS. TCID 50 were determined with BEK cells by limiting dilution. 


\section{Semi-reducing western immunoblotting}

Protein cell extracts were obtained from a six-well confluent plate of HEK 293T transfected with pINT2CMVsyEBOVgD106 and from $25-\mathrm{cm}^{2}$ confluent flasks of BEK infected with BoHV-4- syEBOVgD106 $\Delta$ TK by adding $100 \mu \mathrm{L}$ of cell extraction buffer $(50 \mathrm{mM}$ Tris- $\mathrm{HCl}$, $150 \mathrm{mM} \mathrm{NaCl}$, and 1\% NP-40; pH 8). A 10\% SDS-PAGE gel electrophoresis was used to analyze cell extracts containing $50 \mu \mathrm{g}$ of total protein, after protein transfer in nylon membranes by electroblotting, the membranes were incubated with primary bovine anti BoHV-1 glycoprotein D monoclonal antibody (clone 1B8-F11; VRMD, Inc., Pullman, WA, USA), diluted 1:15.000, and then with a secondary antibody probed with horseradish peroxidase-labelled anti-mouse immunoglobulin (SIGMA), diluted 1:10.000, to be visualized by enhanced chemiluminescence (ECL KIT; PIERCE). Cell supernatant obtained from HEK 293T transfected with pCMVEBOsecgD106 was collected at different time points $(16,24,40,48,50,60$ and $70 \mathrm{~h}$ after transfection) and analyzed as above.

\section{BAC recombineering and selection}

Recombineering was performed as previously described [19] with some modifications. After recombineering, only those colonies that were kanamycin negative and chloramphenicol positive were kept and grown overnight in $5 \mathrm{~mL}$ of LB containing $12.5 \mathrm{mg} / \mathrm{mL}$ of chloramphenicol. BAC DNA was purified and analyzed through HindIII restriction enzyme digestion. DNA was separated by electrophoresis in a $1 \%$ agarose gel, stained with ethidium bromide, and visualized through UV light. Original detailed protocols for recombineering can also be found at the recombineering website (http://recombineering. ncifcrf.gov).

\section{Southern blotting}

DNA from 1\% agarose gel was capillary transferred to a positively charged nylon membrane (ROCHE), and cross-linked by UV irradiation by standard procedures [16].

The membrane was pre-hybridized in $50 \mathrm{~mL}$ of hybridization solution (7\% SDS, $0.5 \mathrm{M}$ phosphate, $\mathrm{pH}$ 7.2) for $1 \mathrm{~h}$ at $65^{\circ} \mathrm{C}$ in a rotating hybridization oven (TECHNA INSTRUMENTS). The 1967 bp amplicon for EBO digoxigenin-labeled probe was generated by PCR with NheI EBOGP sense (5'-ggggctagccaccatgggcgtg- $\left.3^{\prime}\right)$ and SalIEBOGP antisense (5'-ggggtcgacctggcgccagccggtccaccagtt $3^{\prime}$ ) primers, as previously described [12].

\section{Cell culture electroporation and recombinant virus reconstitution}

BEK or BEK cre cells were maintained as a monolayer with complete DMEM growth medium with $10 \%$ FBS,
$2 \mathrm{mM} \mathrm{L}$-glutamine, $100 \mathrm{IU} / \mathrm{mL}$ penicillin and $10 \mathrm{mg} /$ $\mathrm{mL}$ streptomycin. When cells were sub-confluent (7090\%) they were split to a fresh culture flask (i.e., every 3-5 days) and were incubated at $37{ }^{\circ} \mathrm{C}$ in a humidified atmosphere of $95 \%$ air-5\% $\mathrm{CO}_{2}$. BAC DNA (5 $\left.\mu \mathrm{g}\right)$ was electroporated in $600 \mu \mathrm{L}$ DMEM without serum (EQUIBIO APPARATUS, 270 V, 960 mF, 4-mm gap cuvettes) into BEK and BEK cre cells from a confluent $25-\mathrm{cm}^{2}$ flask. Electroporated cells were returned to the flask, after $24 \mathrm{~h}$ the medium was replaced with fresh medium, and cells were split 1:2 when they reached confluence at 2 days post-electroporation. Cells were left to grow until the appearance of CPE. Recombinant viruses were propagated by infecting confluent monolayers of BEK cells at a M.O.I. of 0.5 TCID50/cell and maintaining them in EMEM with 10\% FBS for $2 \mathrm{~h}$.

\section{Viral growth curves}

BEK cells were infected with BoHV-4-A and BoHV4syEBOVgD106 $\triangle \mathrm{TK}$ at a M.O.I. of $0.1 \mathrm{TCID50/cell} \mathrm{and}$ incubated at $37{ }^{\circ} \mathrm{C}$ for $4 \mathrm{~h}$. Infected cells were washed with serum-free EMEM and then overlaid with EMEM containing 10\% FBS, 2 mM L-glutamine, $100 \mathrm{IU} / \mathrm{mL}$ penicillin, $100 \mathrm{mg} / \mathrm{mL}$ streptomycin and 2.5- mg/mL Amphotericin B. The supernatants of infected cultures were harvested after 24, 48, 72 and $96 \mathrm{~h}$, and the amount of infectious virus was determined by limiting dilution on BEK cells.

\section{Samples collection and ELISA procedure}

Blood samples were processed for ELISA test. Briefly, microplates (MICROLON HIGH BINDING) were coated overnight at $4{ }^{\circ} \mathrm{C}$ with $50 \mathrm{ng} /$ well EBOsecgD106 protein supernatant obtained from $175-\mathrm{cm}^{2}$ sub-confluent HEK 293T cells, transfected with pCMVEBOsecgD106 (Additional file 1: Figure S1) and diluted in $0.1 \mathrm{M}$ carbonate/ bicarbonate buffer $\mathrm{pH}$ 9.6. After blocking with $1 \%$ bovine serum albumin (BSA), serum samples at different dilutions $(1 / 10,1 / 100,1 / 1000$ and $1 / 10,000)$ were incubated for $1 \mathrm{~h}$ at room temperature. After three washing steps, $50 \mu \mathrm{L}$ of donkey anti-goat IgG-HRP (SANTA CRUZ BIOTECNOLOGY, Germany) diluted 1:1.000 was added to each well and the plate was incubated as above. Following the final washing step, the reaction was developed with $3,3^{\prime}, 5,5^{\prime}$-tetramethylbenzidine (TMB), stopped with $0.2 \mathrm{M} \mathrm{H}_{2} \mathrm{SO}_{4}$ and read at $450 \mathrm{~nm}$.

\section{Results}

In silico design of an EBOLA virus tagged ORF

The Zaire Ebola virus Mayinga strain glycoprotein (GP) sequence, identical to the Gabon-94 strain and highly conserved with the new isolates (accession number: KJ660346.2, KJ660347, KJ660348), was used as a 
template to obtain its nucleotide sequence by reverse translation, which was human codon usage adapted and tagged at the carboxy-terminal with gD106 tag peptide $[10,20]$ (Fig. 1a, b). Furthermore, a Kozak's sequence (to improve translation) and restriction enzyme sites (to facilitate the sub-cloning in suitable vector) were added to the synthetic ORF antigen (Fig. 1b), which we termed "syEBOVgD106".

\section{Generation and expression of syEBOVgD106 antigen expression cassette}

syEBOVgD106 synthetic ORF was cut out from its plasmid back-bone and sub-cloned in pINT2EGFP [17] shutthe vector containing a CMV-EGFP expression cassette, where EGFP ORF was substituted with syEBOVgD106

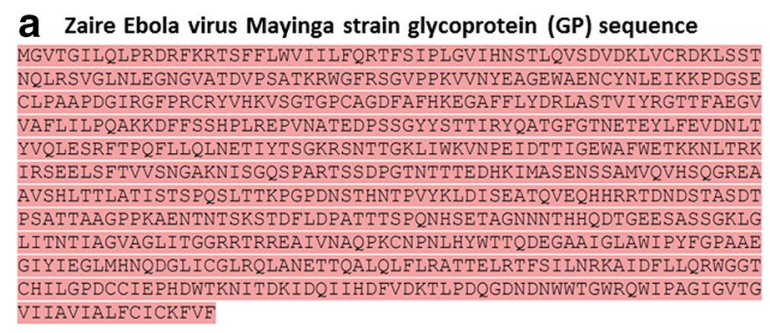

b Reverse translated, human codon usage adapted and tagged ORF SmaI NheI KS

cecggggctagcccacCATGGGCGTGACCGGCATCCTGCAGCTGCCCCGCGACCGCTTCA AGCGCACCAGCTTCTTCCTGTGGGTGATCATCCT GTTCCAGCGCACCTTCAGCATCCCCC TGGGCGTGATCCACAACAGCACCCTGCAGGTGAGCGACGTGGACAAGCTGGTGTGCCGCG ACAAGCT GAGCAGCACCAACCAGCTGCGCAGCGTGGGCCT GAACCTGGAGGGCAACGGCG TGGCCACCGACGT GCCCAGCGCCACCAAGCGCTGGGGCTTCCGCAGCGGCGTGCCCCCCA AGGTGGTGAACTACGAGGCCGGCGAGTGGGCCGAGAACTGCTACAACCTGGAGATCAAGA AGCCCGACGGCAGCGAGTGCCTGCCCGCCGCCCCCGACGGCATCCGCGGCTTCCCCCGCT GCCGCTACGTGCACAAGGTGAGCGGCACCGGCCCCTGCGCCGGCGACTTCGCCTTCCACA AGGAGGGCGCCTTCTTCCTGTACGACCGCCTGGCCAGCACCGTGATCTACCGCGGCACCA CCTTCGCCGAGGGCGTGGTGGCCTTCCTGATCCTGCCCCAGGCCAAGAAGGACTTCTTCA GCTICGCCGAGGGCGTGGTGGCCTTCCTGATCCTGCCCCAGGCCAAGAAGGACTTCTTCA

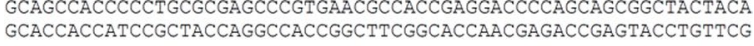
AGGTGGACAACCTGACCTACGTGCAGCTGGAGAGCCGCTTCACCCCCCAGTTCCTGCTGC AGCTGAACGAGACCATCTACACCAGCGGCAAGCGCAGCAACACCACCGGCAAGCTGATCT GGA.AGGTGA.ACCCCGAGATCGACACCACCATCGGCGAGTGGGCCTTCTGGGAGACCAAGA AGAACCTGACCCGCAAGATCCGCAGCGAGGAGCTGAGCTTCACCGTGGTGAGCAACGGCG CCAAGAACATCAGCGGCCAGAGCCCCGCCCGCACCAGCAGCGACCCCGGCACCAACACCA CCACCGAGGACCACAAGATCATGGCCAGCGAGAACAGCAGCGCCATGGTGCAGGTGCACA GCCAGGGCCGCGAGGCCGCCGT GAGCCACCTGACCACCCTGGCCACCATCAGCACCAGCC CCCAGAGCCTGACCACCAAGCCCGGCCCCGAACAACAGCACCCACAACACCCCCGTGTACA AGCTGGACATCAGCGAGGCCACCCAGGTGGAGCAGCACCACCGCCGCACCGACAACGACA AGCAGGACATCAGCGAGGCCACCCAGGTGGAGCAGCACCACCGCCGCACCGACAACGACA CCAACACCAGCAAGAGCACCGACTTCCTGGACCCCGCCACCACCACCAGCCCCCAGAACC ACAGCGAGACCGCCGGCAACAACAACACCCACCACCAGGACACCGGCGAGGAGAGCGCCA GCAGCGGCAAGCT GGGCCTGATCACCAACACCATCGCCGGCGTGGCCGGCCTGATCACCG GCGGCCGCCGCACCCGCCGCGAGGCCATCGTGAACGCCCAGCCCAAGTGCAACCCCAACC TGCACTACTGGACCACCCAGGACGAGGGCGCCGCCATCGGCCTGGCCTGGATCCCCTACT TCGGCCCCGCCGCCGAGGGCATCTACATCGAGGGCCTGATGCACAACCAGGACGGCCTGA COTGCOCG

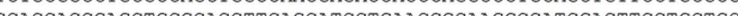
AGCGCTGGGGCGGCACCTGCCACATCCTGGGCCCCGACTGCTGCATCGAGCCCCACGACT GGCACCAGGGAACATCACCGACAAGATCGACCAGATCATCCACGACTTCGTGGACAAGACCC GGACCAAGAACATCACCGACAAGATCGACCAGATCATCCACGACTTGGTGGACAAGACCC GCATCGGCGTGACCGGCGTGATCATCGCCGTGATCGCCCTGTTCTGCATCTGCAAGTTCG TGTTC

Fig. 1 In silico design of EBOV GP synthetic ORF. a Zaire EBOV Mayinga strain GP sequence and $\mathbf{b}$ deduced nucleotide sequence provided of a tag peptide (gD 106; highlighted in red) a Kozak's sequence (KS; highlighted in grey) and restriction enzyme sites (Smal and Nhel; highlighted in yellow) for subcloning
ORF. The resulting construct, pINT2CMV-syEBOVgD106, has two BoHV-4 TK region sequences, flanking the CMV-syEBOVgD106 expression cassette under the transcriptional control of the CMV early promoter and the bovine growth hormone polyadenylation signal sequence (Fig. 2a). The pINT2CMV-syEBOVgD106 construct was validated in terms of protein expression by transient transfection assay in HEK 293T cells and by western blotting using a specific monoclonal antibody against gD106 tag peptide. As expected, syEBOVgD106 glycoprotein was very well expressed in the PINT2CMV-syEBOVgD106 transfected HEK 293T cells (Fig. 2b) and showed the predicted banding pattern (Fig. 2c, d) generated by the cellular metalloprotease TACE [TNF $\alpha$-converting enzyme, a member of the ADAM (a disintegrin and metalloproteinase proteinase family)] and Furin [21, 22].

\section{Vectorization of syEBOVgD106 expression cassette in BoHV-4-based vector}

pINT2CMV-syEBOVgD106 shuttle plasmid construct was employed to generate pBAC-BoHV-4syEBOVgD106 $\triangle \mathrm{TK}$ by heat-inducible homologous recombination in SW102 E. coli containing pBAC-BoHV4-A-KanaGalK $\Delta$ TK (Fig. 3a). KanaGalK negative selected colonies were amplified in liquid media and their respective BAC analyzed by HindIII restriction enzyme and successively by southern hybridization (Fig. 3b) using a specific, non-isotopic labeled probe directed against syEBOVgD106 ORF. pBAC-BoHV-4-syEBOVgD106 $\Delta$ TK stability was assessed by host bacterial serial passages (over 20) and absence of aberrant recombination was detected by restriction enzyme digestion (data not shown).

Infectious BoHV-4-syEBOVgD106 $\Delta \mathrm{TK}$ viral particles were obtained by transfecting, through electroporation, BEK cells or BEK cells expressing cre recombinase (BEKcre) [16] to deplete the BAC cassette from pBACBoHV-4-syEBOVgD106 $\triangle \mathrm{TK}$. In both cases, viable BoHV-4-syEBOVgD106 producing CPE and plaques was generated, although BoHV-4-syEBOVgD106 $\Delta \mathrm{TK}$ produced in BEKcre lost GFP expression due to the removal of GFP expression cassette associated to the BAC plasmid back-bone (Fig. 3c). Next, the growth characteristics of BoHV-4-syEBOVgD106 $\Delta \mathrm{TK}$ were compared with that one of the BoHV-4-A parental virus and no differences between them were observed (Fig. 3d). Furthermore, BoHV-4-syEBOVgD106 $\Delta$ TK infected cells expressed syEBOVgD106 glycoprotein (Fig. 3e). Since the EBOV GP is a typical, type 1 integral membrane glycoprotein, its ability to be incorporated on the BoHV-4 envelope was investigated. A virus preparation from BoHV-4A-CMV-IgK-gE2gD-TM was purified and analyzed 


\section{a}
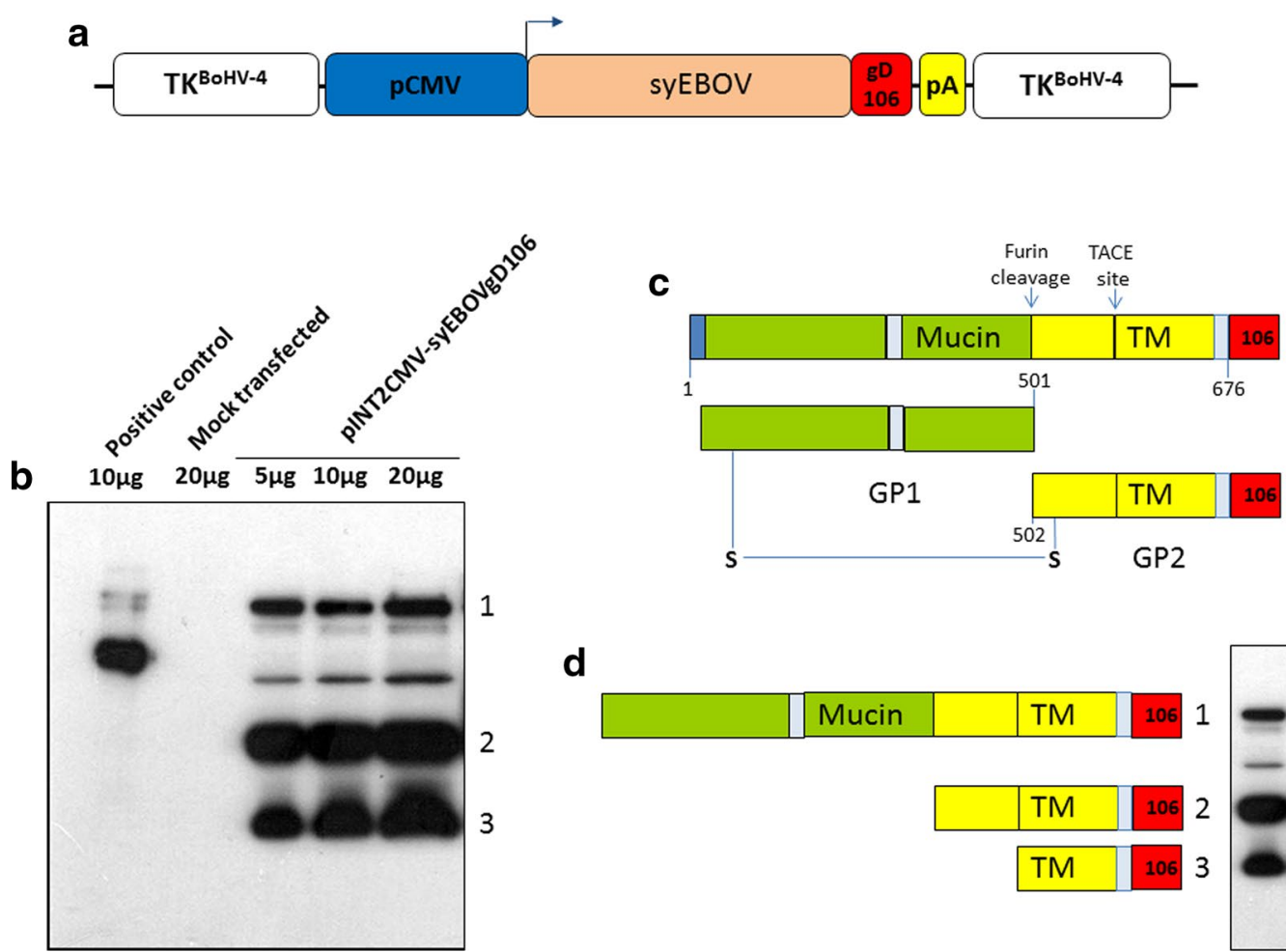

1

d

3

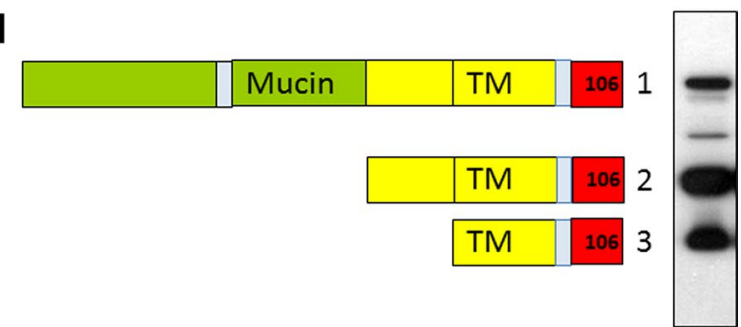

Fig. 2 Expression of syEBOVgD106. a Diagram (not on scale) of pINT2CMV-syEBOVgD106 targeting vector delivering the tagged syEBOVgD106 ORF (syEBOV, orange; gD106, red), under the control of the CMV promoter (CMV, blue) and the bovine growth hormone polyadenylation signal (PA, yellow). CMV-syEBOVgD106 expression cassette is flanked by BoHV-4 TK homologous sequences (white). b Western immunoblotting of plNT2CMVsyEBOVgD106 transfected HEK 293T cells extracts. Lanes were loaded with different amounts of total protein cell extract $(5,10$ and $20 \mu \mathrm{g})$; cells transfected with pEGFPC-1 served as negative controls (Mock). The peculiar immune-blotting banding pattern is the result of the syEBOVgD106 protein processing by furin and TACE proteases $(\mathbf{c})$, as revealed by the anti gD106 tag monoclonal antibody directed against three predicted and detected peptides ( 1 uncleaved; 2 only cleaved by Furin protease; 3 cleaved by Furin and TACE proteases) (d)

by Western immunoblotting (Additional file 2: Figure S2). As expected, EBOV GP signal was detected only in BoHV-4-syEBOVgD106 $\triangle$ TK virions, but not in the wildtype BoHV-4 virions, thus indicating the incorporation of syEBOVgD106 into BoHV-4 virus particles.

\section{Goat immunization and humoral immune-response analysis}

For testing the ability of BoHV-4-syEBOVgD106 $\Delta \mathrm{TK}$ to induce a humoral immune response in a large animal model, a pilot immunization study was performed in goats. In agreement with the current legislation on animal experimentation, which suggests to minimize the number of animals employed, three adult goats, after collection of the pre-immune serum, were inoculated subcutaneously with $1 \mathrm{~mL}$ of $10^{6}$ TCID50 of BoHV4-syEBOVgD106 TKK. A second inoculation with an identical dose of BoHV-4-syEBOVgD106 $\Delta \mathrm{TK}$ was done 2 weeks apart from the first inoculation. Blood samples were collected at two, just before the second inoculum, and 5 weeks from the first inoculum (Fig. 4a).
Serum samples were analyzed by ELISA and all three goats developed a very good antibody response, with high titers (Fig. 4b, c). As previously described for BoHV-4-based vaccine vector inoculation in goats [15], in the present study, a single inoculation of BoHV4-syEBOVgD106 $\Delta \mathrm{TK}$ was able to elicit a humoral immune response 2 weeks post inoculation. Moreover, the antibody titer did not decrease when evaluated 6 months later (data not shown), showing long lasting immunization.

\section{Discussion}

In this work, the potential utility of BoHV-4 as a safe, potent, large-capacity gene delivery vector for EBOV antigen was shown. A workflow strategy to construct a BoHV-4-based vector was generated and it was able to deliver an immune-dominant antigen derived from a BSL4 pathogen, thus avoiding all the economical and safety requirements necessary for the manipulation of this kind of biological agent. Furthermore, it was able to elicit a strong humoral immune-response. The results 

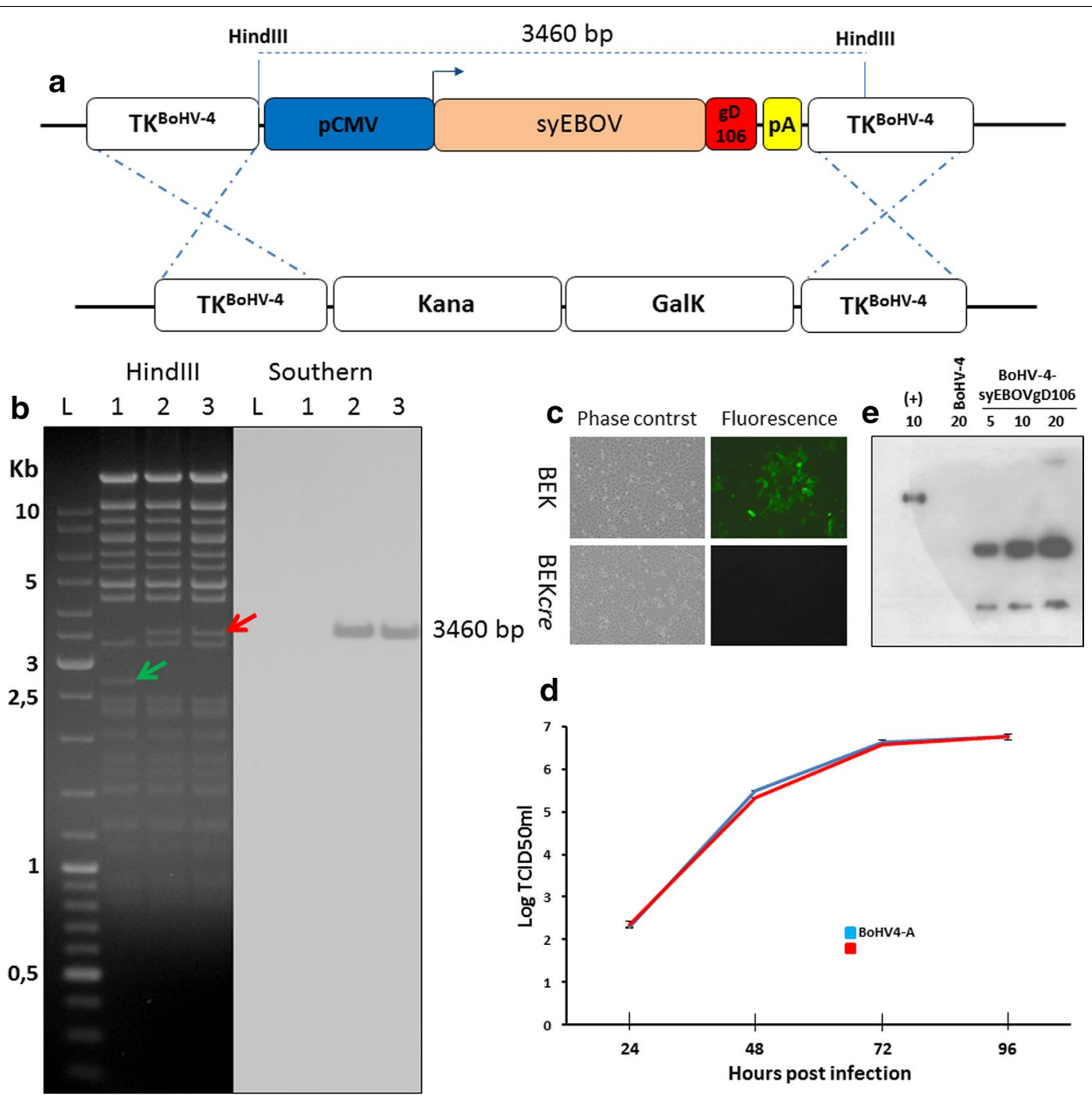

Fig. 3 BoHV-4-syEBOVgD106 $\triangle T K$ constructs and characterization. a Diagram (not to scale) illustrating the re-targeting event (i.e., replacement of the Kana/GalK cassette with the CMV-syEBOVgD106 cassette) obtained by heat-inducible homologous recombination in SW102 E. coli cells containing pBAC-BoHV-4-A-TK-KanaGalK-TK. b Representative, 2-deoxy-galactose resistant colonies, tested by Hindlll restriction enzyme analysis and southern blotting performed with a specific probe for syEBOVgD106 ORF. The 2650 bp band (indicated by a green arrow) corresponding to the non-retargeted pBAC-BoHV-4-A-TK-KanaGalK-TK control (lane 1) is replaced by 3460 bp band (indicated by a red arrow) in pBAC-BoHV-4syEBOVgD106 $\triangle T K$ (lanes 2 and 3). Phase contrast and fluorescent microscopy images of the plaques formed by viable, reconstituted recombinant BoHV-4-syEBOVgD106 $\triangle T K$ (c) after electroporation of the corresponding BAC DNA clones into BEK or BEKcre cells (magnification, $\times 10)$. d Replication rate of BoHV-4-syEBOVgD106 $\triangle \mathrm{TK}$ grown in BEK cells and compared with that of the parental BoHV-4-A isolate. The data are the mean \pm standard error of triplicate measurements ( $P>0.05$ for all time-points; Student's $t$ test). e Immunoblotting analyses conducted on extracts from cells infected with BoHV-4-syEBOVgD106 $\triangle T K$ (numbers indicate the micrograms of total protein loaded). BoHV-4-A infected cells served as negative controls

were obtained through a synthetic gene approach, currently based on solid-phase DNA synthesis, which allows the complete synthesis of a double-stranded DNA molecule with no apparent limits in nucleotide sequence or size.

As a model pathogen, EBOV was the primary choice. Firstly because a severe Ebola outbreak was taking place in African countries at the beginning of this project and at that time no approved prophylactic or therapeutic protocols were available. Secondly, EBOV it is classified as a Category A priority pathogen by NIAID and a Category A agent of bioterrorism by the CDC.

The EBOV genome is a single negative-strand RNA molecule encoding seven structural proteins, among which EBOV GP is a type I transmembrane glycoprotein of 676 amino acids in length and its transcript is made 

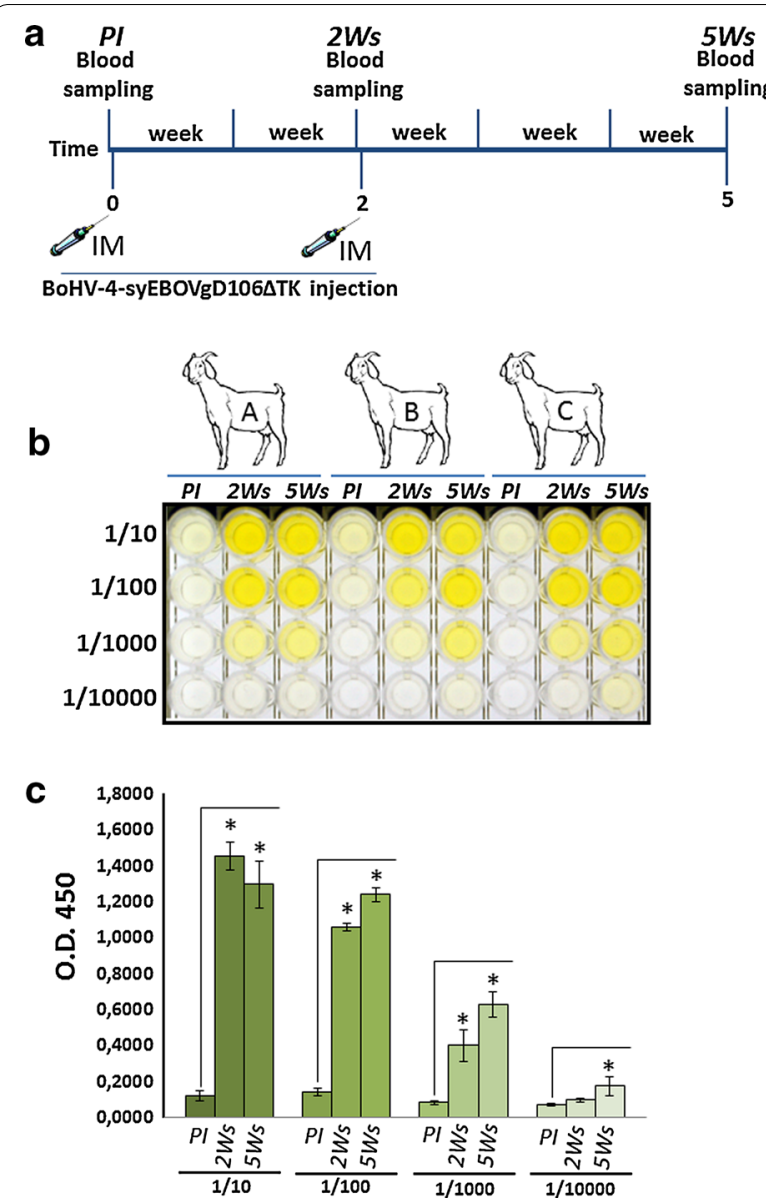

Fig. 4 Kinetics of the humoral immune responses of goats immunized with BoHV-4-syEBOVgD106 $\triangle T K$. a Diagram showing the goats immunization scheme and blood sample collection. b Dilutes sera $(1 / 10,1 / 100,1 / 1000$ and $1 / 10,000)$ collected at 2 and 5 weeks ( $2 \mathrm{Ws}$; $5 \mathrm{Ws}$ ) from three (A, B and C) BoHV-4-syEBOVgD106 $\triangle T K$ inoculated goats, were compared with pre-immune sera (PI) for anti-GP antibodies by ELISA. c Antibodies detected were expressed as the optical density at $450 \mathrm{~nm}$ and each value represents the mean response of the three goats sera, \pm the standard error of the mean, at the same dilution and collected at the same time. Response differences between pre- and post-immune sera were measured by Student's $t$ test $\left({ }^{*} \mathrm{P} \leq 0.005\right)$

by an unusual transcriptional editing [23]. Full length GP has been shown to be responsible for eliciting a protective humoral immune response in infected individuals [8]. The cleavage of surface GP, by cellular metalloprotease, tumor necrosis factor $\alpha$-converting enzyme (TACE), generates shed GP [21], which contributes to the host protective immune response [22]. Firstly, in silico customized full length GP ORF was successfully expressed in eukaryotic cells with a suitable expression vector and then integrated in BAC BoHV-4 genome through homologous recombination. BoHV-4-syEBOVgD106 $\Delta \mathrm{TK}$ replicated in cell culture at the same extent as the parental virus, thus no detrimental effect induced by the topological location of the foreign DNA in the BoHV-4 genome was observed. BoHV-4 is a Gammaherpesvirus belonging to the Rhadinovirus genera. Although BoHV-4 natural host is cattle, the virus has been isolated from other ruminants, including zebu (Bos indicus), American bison (Bison bison), African buffalo (Syncerus caffer), and sheep. Like other Herpesviruses, BoHV-4 is able to establish persistent infection in cells of the monocyte/macrophage lineage [24,25] and in a bovine macrophage cell line (BoMAC) [26]. Furthermore, BoHV-4 experimental inoculation in rabbit demonstrates how spleen, as well as macrophages, are the main site of viral persistence [27]. Due to the lack of a direct correlation between BoHV-4 infection and specific lesions or pathology, BoHV-4 is not considered a primary pathogen and its genome was cloned as bacterial artificial chromosome (BAC), in order to be exploited as a gene delivery vector for immunization purposes and oncolysis. BoHV-4-based vector delivering antigens have been employed to immunize mice [9], rats [11], rabbits [12], sheep [13], swine [14], cows (paper in preparation) and goats [15] without any associated clinical signs or pathology.

Although goats are not susceptible to EBOV infection, BoHV-4-syEBOVgD106 $\mathrm{TK}$ immunization was performed in adults goats as they have previously been shown to be an appropriate large animal model for BoHV-4-based vector immunization [15]. Further, goats could be exploited as a source of antibodies production for antibody-based therapeutic in post-exposure treatment of EBOV disease. A pair of newly published studies $[28,29]$, demonstrated the efficacy of an ovine polyclonal antibody therapy against EBOV disease when tested in the stringent guinea pig model of EBOV disease.

The sub-cutaneous route of BoHV-4-based vector administration was shown to facilitate antigen production and vector replication takes place only at the site of inoculation [15], without spreading to the rest of the animal body. No BoHV-4-syEBOVgD106 $\Delta \mathrm{TK}$ viremia was detected in inoculated animals, although all BoHV-4syEBOVgD106 $\triangle \mathrm{TK}$ inoculated animals were successfully immunized and high titers of EBOV GP antibodies were detected. The ability of BoHV-4-syEBOVgD106 $\Delta$ TK to efficiently transduce goat skin cells, which consecutively expressed large amounts of GP, explains the consistent titer of antibodies produced and detected by the ELISA assay.

Whether the antibodies induced by BoHV-4syEBOVgD106 $\Delta \mathrm{TK}$ in goats serum, correlates with a potential protection following a passive transfer in a suitable stringent model of EBOV disease remains unknown. Based on previous studies, which demonstrated the ability of BoHV-4 based vectors to efficiently protect against 
the Category A agent Monkeypox virus [10], it can be assumed that the use of BoHV-4 vector based platform represents an effective tool to test unknown antigens and vectors for class A pathogens.

\section{Conclusion}

In this study, the possibility to generate a BoHV-4-based vector delivering an immune-dominant antigen coming from EBOV and proven to be able to generate high titer of antibodies in inoculated goats was shown.

\section{Additional files}

Additional file 1: Figure S1. Overall strategy employed for cloning and expression of EBOV GP as a soluble secreted form. A Diagram (not to scale) showing the structure of gD106 tagged (red) EBOV GP. The EBOsecgD106 has been obtained by eliminating the transmembrane domain (TM). EBOsecgD106 peptide has been produced in serum free medium of HEK 293T cells transfected with pCMVEBOsecgD106. B A time course to optimize EBOsecgD106 expression at different time post transfection as analyzed by western immunoblotting was used. Twenty-four hours was considered as the best time post transfection to collect the cell sovranatant.

Additional file 2: Figure S2. Incorporation of EBOV GP into recombinant BoHV-4 particles. Extracts of purified viruses (BoHV-4-A and BoHV-4-syEBOVgD 106) analyzed by Western immunoblotting.

\begin{abstract}
Abbreviations
EBOV: Ebola virus; BoHV-4: bovine herpesvirus 4; GP: glycoprotein; ELISA: enzyme linked immunosorbent assay; ORF: open reading frame; CFR: case fatality report; rVSV: recombinant vesicular stomatitis virus; ZEBOV $\triangle \mathrm{G}$ : Zaire EBOV glycoprotein; rAd5: recombinant adenovirus serotype 5; rChAd3: recombinant chimpanzee adenovirus serotype 3; rHPIV3: recombinant human parainfluenza virus 3; BAC: bacterial artificial chromosome; BSL: biosafety level; BEK: bovine embryo kidney; HEK 293T: human embryo kidney 293T; EMEM: Eagle's minimal essential medium; FBS: fetal bovine serum; EBOsec: EBOV secreted fragment; PEl: polyethylenimine; DMEM: Dulbecco's modified essential medium; MOI: multiplicity of infection; $\mathrm{TCID}_{50}$ : tissue culture infectious doses 50; CPE: cytopathic effect; SDS-PAGE: sodium dodecyl sulfate-polyacrylamide gel electrophoresis; BoHV-1: bovine herpesvirus 1; HRP: horseradish peroxidase; LB: Luria-Bertani; BSA: bovine serum albumin; TMB: tetramethylbenzidine; TK: thymidine kinase; TACE: tumor necrosis factor a-converting enzyme; Pl: pre-immune; BoMAC: bovine macrophage cell line; FDA: Food and Drug Administration; PA: polyadenylation.
\end{abstract}

\section{Authors' contributions}

DG conceived the experiments. AR, SJ, GT, ST, VF, FM and DG performed the experiments. SC and GK contributed with reagents. GD and DPK analysed the data. GD wrote the paper. All authors read and approved the final manuscript.

\section{Author details}

1 Department of Medical-Veterinary Science, University of Parma, Via del Taglio 10, 43126 Parma, Italy. ${ }^{2}$ Special Pathogens Program, University of Manitoba and Public Health Agency of Canada, Winnipeg, MB, Canada. ${ }^{3}$ Animal Disease Research Unit, Agricultural Research Service, United States Department of Agriculture, and Department of Veterinary Microbiology \& Pathology, Washington State University, Pullman, WA, USA.

\section{Acknowledgements}

We would like to tank Dr. Laura Kramer for the English editing of the manuscript

\section{Competing interests}

The authors declare that they have no competing interests.
Availability of data and materials

Available under request.

\section{Ethics approval and consent to participate}

Adult goats were used for the in vivo immunization study. Animal experimentation was conducted under the approval of the Ethical Committee of the University of Parma and the Italian Ministry of Health and it was carried out at the University of Parma, which follows the guidelines of the National Guide for Care and Use of Experimental Animals (n. 3/2014). The Animal Care and Use Program at Parma University are fully accredited by the European Accreditation of Laboratory Animal Care.

\section{Funding}

This work was supported by Italian Ministry of University and Scientific Research (Italian National Grant MIUR, PRIN 2010-2011).

Received: 4 May 2016 Accepted: 14 November 2016

Published online: 24 November 2016

\section{References}

1. de La Vega MA, Wong G, Kobinger GP, Qiu X. The multiple roles of sGP in Ebola pathogenesis. Viral Immunol. 2015;28:3-9.

2. Martines RB, Ng DL, Greer PW, Rollin PE, Zaki SR. Tissue and cellular tropism, pathology and pathogenesis of Ebola and Marburg viruses. J Pathol. 2015;235:153-74.

3. Stanley DA, Honko AN, Asiedu C, Trefry JC, Lau-Kilby AW, Johnson JC, Hensley L, Ammendola V, Abbate A, Grazioli F, et al. Chimpanzee adenovirus vaccine generates acute and durable protective immunity against ebolavirus challenge. Nat Med. 2014;20:1126-9.

4. Ledgerwood JE, Costner P, Desai N, Holman L, Enama ME, Yamshchikov G, Mulangu S, Hu Z, Andrews CA, Sheets RA, et al. A replication defective recombinant Ad5 vaccine expressing Ebola virus GP is safe and immunogenic in healthy adults. Vaccine. 2010;29:304-13.

5. Meyer M, Garron T, Lubaki NM, Mire CE, Fenton KA, Klages C, Olinger GG, Geisbert TW, Collins PL, Bukreyev A. Aerosolized Ebola vaccine protects primates and elicits lung-resident T cell responses. J Clin Investig. 2015;125:3241-55.

6. Johnson RF, Kurup D, Hagen KR, Fisher C, Keshwara R, Papaneri A, Perry $\mathrm{DL}$, Cooper K, Jahrling PB, Wang JT, et al. An inactivated rabies virus-based Ebola vaccine, FILORAB1, adjuvanted with glucopyranosyl lipid A in stable emulsion confers complete protection in nonhuman primate challenge models. J Infect Dis. 2016;214:S342-54.

7. Henao-Restrepo AM, Longini IM, Egger M, Dean NE, Edmunds WJ, Camacho A, Carroll MW, Doumbia M, Draguez B, Duraffour S, et al. Efficacy and effectiveness of an rVSV-vectored vaccine expressing Ebola surface glycoprotein: interim results from the Guinea ring vaccination clusterrandomised trial. Lancet. 2015;386:857-66.

8. Mire CE, Matassov D, Geisbert JB, Latham TE, Agans KN, Xu R, Ota-Setlik A, Egan MA, Fenton KA, Clarke DK, et al. Single-dose attenuated vesiculovax vaccines protect primates against Ebola Makona virus. Nature. 2015;520:688-91.

9. Franceschi V, Capocefalo A, Calvo-Pinilla E, Redaelli M, Mucignat-Caretta C, Mertens P, Ortego J, Donofrio G. Immunization of knock-out alpha/ beta interferon receptor mice against lethal bluetongue infection with a BoHV-4-based vector expressing BTV-8 VP2 antigen. Vaccine. 2011;29:3074-82.

10. Franceschi V, Parker S, Jacca S, Crump RW, Doronin K, Hembrador E, Pompilio D, Tebaldi G, Estep RD, Wong SW, et al. BoHV-4-based vector single heterologous antigen delivery protects STAT1 $(-/-)$ mice from monkeypoxvirus lethal challenge. PLoS Negl Trop Dis. 2015;9:e0003850.

11. Donofrio G, Martignani E, Poli E, Lange C, Martini FM, Cavirani S, Cabassi CS, Taddei S, Flammini CF. Bovine herpesvirus 4 based vector interaction with liver cells in vitro and in vivo. J Virol Methods. 2006;136:126-36.

12. Donofrio G, Franceschi V, Capocefalo A, Taddei S, Sartori C, Bonomini S, Cavirani S, Cabassi CS, Flammini CF. Cellular targeting of engineered heterologous antigens is a determinant factor for bovine herpesvirus 4-based vaccine vector development. Clin Vaccine Immunol. 2009:16:1675-86 
13. Donofrio G, Sartori C, Ravanetti L, Cavirani S, Gillet L, Vanderplasschen A, Taddei S, Flammini CF. Establishment of a bovine herpesvirus 4 based vector expressing a secreted form of the bovine viral diarrhoea virus structural glycoprotein E2 for immunization purposes. BMC Biotechnol. 2007;7:68.

14. Donofrio G, Taddei S, Franceschi V, Capocefalo A, Cavirani S, Martinelli N, Ottonello S, Ferrari M. Swine adipose stromal cells loaded with recombinant bovine herpesvirus 4 virions expressing a foreign antigen induce potent humoral immune responses in pigs. Vaccine. 2011;29:867-72.

15. Donofrio G, Franceschi V, Lovero A, Capocefalo A, Camero M, Losurdo M, Cavirani S, Marinaro M, Grandolfo E, Buonavoglia C, Tempesta M. Clinical protection of goats against CpHV-1 induced genital disease with a BoHV4-based vector expressing CpHV-1 gD. PLoS ONE. 2013;8:e52758.

16. Donofrio G, Sartori C, Franceschi V, Capocefalo A, Cavirani S, Taddei S, Flammini CF. Double immunization strategy with a BoHV-4-vectorialized secreted chimeric peptide BVDV-E2/BoHV-1-gD. Vaccine. 2008;26:6031-42.

17. Donofrio G, Cavirani S, Simone T, van Santen VL. Potential of bovine herpesvirus 4 as a gene delivery vector. J Virol Methods. 2002;101:49-61.

18. Donofrio G, Cavaggioni A, Bondi M, Cavirani S, Flammini CF, MucignatCaretta C. Outcome of bovine herpesvirus 4 infection following direct viral injection in the lateral ventricle of the mouse brain. Microbes Infect. 2006;8:898-904

19. Warming S, Costantino N, Court DL, Jenkins NA, Copeland NG. Simple and highly efficient BAC recombineering using galK selection. Nucleic Acids Res. 2005;33:e36.

20. Capocefalo A, Franceschi V, Mertens PP, Castillo-Olivares J, Cavirani S, Di Lonardo E, Leni Z, Donofrio G. Expression and secretion of Bluetongue virus serotype 8 (BTV-8)VP2 outer capsid protein by mammalian cells. J Virol Methods. 2010;169:420-4.
21. Escudero-Perez B, Volchkova VA, Dolnik O, Lawrence P, Volchkov VE. Shed GP of Ebola virus triggers immune activation and increased vascular permeability. PLoS Pathog. 2014;10:e1004509.

22. Dolnik O, Volchkova VA, Escudero-Perez B, Lawrence P, Klenk HD, Volchkov VE. Shedding of Ebola virus surface glycoprotein is a mechanism of selfregulation of cellular cytotoxicity and has a direct effect on virus infectivity. J Infect Dis. 2015;212(Suppl 2):S322-8.

23. Volchkov VE, Becker S, Volchkova VA, Ternovoj VA, Kotov AN, Netesov SV, Klenk HD. GP mRNA of Ebola virus is edited by the Ebola virus polymerase and by T7 and vaccinia virus polymerases. Virology. 1995;214:421-30.

24. Osorio FA, Reed DE, Rock DL. Experimental infection of rabbits with bovine herpesvirus-4: acute and persistent infection. Vet Microbiol. 1982;7:503-13.

25. Osorio FA, Rock DL, Reed DE. Studies on the pathogenesis of a bovine cytomegalo-like virus in an experimental host. J Gen Virol. 1985;66(Pt 9):1941-51.

26. Donofrio G, van Santen VL. A bovine macrophage cell line supports bovine herpesvirus-4 persistent infection. J Gen Virol. 2001;82:1181-5.

27. Lopez OJ, Galeota JA, Osorio FA. Bovine herpesvirus type-4 (BHV-4) persistently infects cells of the marginal zone of spleen in cattle. Microb Pathog. 1996;21:47-58.

28. Dowall SD, Bosworth A, Rayner E, Taylor I, Landon J, Cameron I, Coxon R, Al Abdulla I, Graham VA, Hall G, et al. Post-exposure treatment of Ebola virus disease in guinea pigs using EBOTAb, an ovine antibody-based therapeutic. Sci Rep. 2016;6:30497.

29. Dowall SD, Callan J, Zeltina A, Al-Abdulla I, Strecker T, Fehling SK, Krahling V, Bosworth A, Rayner E, Taylor I, et al. Development of a cost-effective ovine polyclonal antibody-based product, EBOTAb, to treat Ebola virus infection. J Infect Dis. 2016;213:1124-33.

\section{Submit your next manuscript to BioMed Central and we will help you at every step:}

- We accept pre-submission inquiries

- Our selector tool helps you to find the most relevant journal

- We provide round the clock customer support

- Convenient online submission

- Thorough peer review

- Inclusion in PubMed and all major indexing services

- Maximum visibility for your research

Submit your manuscript at www.biomedcentral.com/submit
O Biomed Central 